\title{
Race From the Inside: An Emerging Heterogeneous Race Model
}

\section{Aaron Celious and Daphna Oyserman*}

University of Michigan

Race matters, influencing life experiences. Race is not a simple concept, and it is not a single category. Racial identity theories, however, typically handle race as a simple Black-White dichotomy that overlooks within-group heterogeneity, substituting a subgroup-young, low socioeconomic status, darker skinned men-for all African Americans. The centrality of this subgroup image reifies what it means to be Black but excludes African Americans who are women, middle class, and so on. We provide an overview of the situation of African Americans, highlighting within-group diversity in everyday experiences related to gender, socioeconomic status, and physical attributes, including skin tone. Understanding the implications of race from an insider's perspective requires that we view it as a heterogeneous category.

But whether it was mainly the skin color, the hair texture, the family background, the education, the money, or the sharpness of our features that set some of us apart and made some of us think we were superior to other blacks - and to most whites-we were certain that we would always be able to recognize our kind of people.

—Graham, 1999, p. 5

*While writing this grant, the authors were partially funded by National Institute of Mental Health Grant No. R01 MH57495, to Oyserman. Celious was also funded by a National Science Foundation Graduate Research Fellowship and Oyserman was also funded by a Research Scholar's award from the W. T. Grant Foundation and by an NIMH grant to James Jackson of the African American Mental Health Research Program. Oyserman is grateful for the support provided by the Center for Advanced Studies in the Behavioral Sciences.

Correspondence concerning this article should be addressed to Daphna Oyserman, Institute for Social Research, University of Michigan, Ann Arbor, MI 48109 [e-mail: daphna@umich.edu]. 
In contemporary America, race, social status and culture are tightly interwoven concepts; difference in color is assumed to carry with it cultural and economic difference (Hollinger, 1999). Moreover, race is constructed as a Black/White issue; when people think of race in America, "Blacks" are contrasted with "Whites" as if each were a homogeneous group. Constructing race in this manner allows for generalizations about the "Black community," racial identity, and its consequences (Balibar, 1996). This simple construction of race is functional because race is an important summarizing factor. By asking questions about the experience of race and being Black in America, social scientists have pointed to the link between race and disparities in health (Williams \& Collins, 1995), wealth (Oliver \& Shapiro, 1995), and educational attainment (Nettles \& Perna, 1997). This research suggests belonging to the social category "African American" shapes everyday life and life experiences. It does little, however, to illustrate the multiple experiences of being Black in the United States that differ based on class, gender, and physical distinctions, namely, skin tone.

Building on essays and an emerging empirical literature, in the current article we propose that it is time we move beyond simple racial dichotomies and begin unpacking differences among African Americans so that the experiences of being Black in America can be better understood. In line with the opening quote from L. Graham (1999), we will argue that African Americans do not experience race as a monolithic single state. African Americans distinguish between themselves and Whites, to be sure, but they also distinguish between and among themselves based on physical features such as socioeconomic status (SES), gender, and skin tone. Not only do African Americans perceive these differences to matter; there is also evidence that these distinctions do matter. For example, economic gaps between light- and dark-skinned African Americans in education, income, and SES are of the same magnitude as the White/Black gap (M. Hughes \& Hertel, 1990; Keith \& Herring, 1991).

In the current article, we argue first that current theorizing is helpful in providing insight into the ways that majority group members treat blacks: as if they were all the same. Yet, this theorizing does not adequately recognize the ways that African Americans' experiences and identity may be heterogeneous. And second, we argue that these differences, between poor and wealthy, between women and men, between dark- and light-skinned African Americans, are large enough that the experience of being Black in America can better be thought of as multiple experiences rather than one experiential state. By taking these differences seriously, we can better understand the ways race influences identity, motivation, and experiences as well as the impact of stereotypes.

Heterogeneity among African Americans is like heterogeneity within other American groups. A similar argument can be made for upwardly mobile African Americans as is made for other upwardly mobile Americans for whom race, creed, ethnic and religious traditions have tended to recede in centrality, ceasing to bind 
individuals to jobs, neighborhoods, and life paths (Gans, 1996). Whereas in previous generations it was assumed that being African American would always set an immutable structure to one's life and daily experience, following Gans (1996), it seems plausible today that racial identity differs between upwardly mobile, middle-class African Americans and less mobile, working- and lower-class Blacks. For the former, race, and racial identity can be symbolic, switched into, or deemphasized depending on context; for the latter, race may be a more omnipresent and concrete force that shapes all of everyday life. In this way, the experience of being Black in high-poverty, high-unemployment inner cities is likely to differ from the experience of being a Black professional. We explore other ways that being Black in America differs given the relationship among material status, gender, and skin tone.

To make sense of within-group differences associated with gender and social and economic status among African Americans, we propose a heterogeneous racial group perspective for studying race because it highlights the need for investigators to recognize distinctions among people of the same racial group. We will also use this perspective to outline ways that skin tone and physical appearance, as markers of status and beauty, influence the everyday experiences of "very dark" and "very light" African American women and men, using examples from both workplace and interpersonal contexts.

\section{Homogeneous and Heterogeneous Racial Group Perspectives}

Race as a social category is built on the assumption that there is some important level of ingroup homogeneity: Stereotypes and prejudices are of course built on the assumption of within-group sameness in traits, features, abilities, and so on. In much the same way, theories of racial identity, like other social categorization theories, assume important constancy in the experience of being a group member, with ingroup and outgroup being the salient or sole focus of comparison. For example, Afrocentric culture is contrasted with European culture (Asante, 1980), with the suggestion that an African cultural frame is more collective and interdependent whereas a European cultural frame is more individual and personally competitive.

Although these ways of contrasting Black with White are of value, it is likely that they oversimplify and overstate homogeneity. They imply that being Black always means being interdependent so that competing in school or the workplace either is "not Black" or requires becoming "raceless" (Fordham, 1988). Indeed, some European Americans may prefer to claim school achievement as a "White" characteristic, and some African Americans may attempt to reinforce strict "Black"-"White" distinctions, disparaging school success as "acting White" (Arroyo \& Zigler, 1995). But empirical research suggests greater complexity; for example, in this issue, Schmader, Major, and Gramzow discuss evidence that 
feelings of racial prejudice are related to disengaging from school so that success or failure is less self-defining.

These perspectives suggest that racial identity is linked to feelings of connection to ingroup members and feelings of racism or exclusion from outgroup members (see also Whittler, Calantone, \& Young, 1991, which explicitly focuses on degree of connection to the "Black community" as a single group). Yet it seems unlikely that African American identity would contain only the communal portion of being African and not also the personal-striving portion of being American, particularly among the academically and occupationally successful middle class (Oyserman, Coon, \& Kemmelmeier, in press). Indeed, among college students, no evidence of higher collectivist or group orientation is found for African American versus European American students (Coon \& Kemmelmeier, in press). These results imply that social class and educational attainment, and not race alone, influence individual versus collective focus of identity. Further, recent research examining content of racial identity as it relates to academic achievement among males and females finds that middle and high school girls and boys differ in content of racial identity and the perceived relationship between being Black and doing well in school (S. Graham, 1994; Oyserman, Harrison, \& Bybee, in press).

Central theories of racial identity-Cross' nigrescence theory (Cross, 1971; Cross \& Fhagen-Smith, 1996), Crocker's collective self-esteem theory (Crocker, 1999; Crocker, Luhtanen, Blaine, \& Broadnax, 1994), and Phinney's racial identity theory (Phinney, 1992, 1996) fail to consider this diversity as relevant to racial identity. Though components of racial identity are described in these theories, they fail to map out the potential for different content of identity for those who experience race as middle or upper class versus poor or working class, as women versus men, and for those with lighter versus darker skin. Thus, for example, Cross's earlier work describes stages of identity development in which individuals move from not realizing that race is central to centralizing race in their lives (Cross, 1971). Though revised to suggest that individuals may in fact vary in the centrality of race without causing problems to their mental health (Cross \& Fhagen-Smith, 1996); this theory does not deal with the ways class, gender, and physical attributes create systematic differences in the experience of being African American.

Similarly, although Crocker and her colleagues (Crocker, 1999; Crocker et al., 1994) highlight the multidimensionality of racial identity, ${ }^{1}$ the notion that different groups are brought to mind depending on class, gender, or physical attributes is never mentioned. Furthermore, Phinney's $(1992,1996)$ illustration of ethnic identity composed of a sense of belonging, identity achievement, and ethnic behaviors

\footnotetext{
${ }^{1}$ Components include a person's private evaluation of the group, the way others evaluate the group, how important group identity is to the individual, and how good a group member he or she is.
} 
does not indicate how this will be experienced differently based on class, gender, or physical appearance. The conclusion drawn from this racial identity literature is that race will be experienced similarly for individuals as a homogenous group regardless of their economic conditions, gender, or physical appearance.

In the case of the social category "Black," the assumption is that the content and consequences of racial identity and of outgroup stereotyping are similar enough that one can talk about "Black identity" or the "Black experience." Although clearly social identity theories do not require that there be a single "Black identity" in practice, researchers and theorists have proceeded as if there were a single identity, a single sense of ingroup solidarity and a single experience of racism. Our goal is to highlight and reclaim the heterogeneity of Black experiences, with particular emphasis on the interface between social class, gender, and physical appearance, especially skin tone, and the consequences of taking these three dimensions into account simultaneously for understanding race, racial identity, and its consequences.

\section{Social Class Differences}

In research and popular culture, there is the tendency to focus on negative, instead of positive, stereotypes about African Americans and to conflate all African Americans with impoverishment. Specific stereotypes about African Americans include low intelligence and aggressiveness and musicality and "coolness" (Wood \& Chesser, 1994), as well as more obviously poverty-linked attributes such as being poor, single, welfare dependent, out of work, or an absentee father (for early examples see Elliot Leibow's Tally's Corner, 1967; Moynahan, 1971). Focusing on these negative stereotypes in scholarship and popular culture is problematic, not because the images are never true, but because these images are portrayed as if they represent all Blacks. This presents a distorted homogeneous view of what it means to be Black in both academics and popular culture. As such, when images and experiences are presented that contradict these stereotypes, as The Cosby Show did in the 1980s, they are popularly redefined as "not really" Black, imaginary or unique cases, rather than legitimate experiences. ${ }^{2}$ Disentangling the Black middle-class experience from the Black lower-class experience is necessary to understand the different ways race is experienced for African Americans. To do this we address some of the benefits and negative consequences homogenous constructions of African Americans have for middle-class and lower-class Blacks.

\footnotetext{
2 This show presented a two-parent, stable, upper-middle-class Black family.
} 
Evidence of any perceivable benefits to lower-class Blacks, based on the homogenous construction of race, has not been found. In contrast, the Black middle class benefits primarily because they are able to enter educational institutions and occupations once barred to African Americans. These educational and occupational opportunities are a result of government efforts to quell inner-city rioting that occurred during the 1960s (Quadagno, 1994). Specifically, these programs were created to give poor Blacks more skills, education, and occupational opportunities; yet, they have served instead to provide greater skills, education and occupational opportunities to working- and primarily middle-class African Americans (Wilson, 1987). Benefits of these programs included the ability of Blacks to secure better wages and move to less segregated communities.

Negative consequences of the homogeneous negative stereotypes about Blacks may be particularly harsh for lower-class Blacks who, viewed as being prone to criminality, social misconduct, immorality, and lack of intelligence (Massey \& Denton, 1993), are at risk of being excluded from neighborhoods, schools, and perhaps most importantly jobs. Kirschenman and Neckerman (1991) found this to be especially true for Black men from poor communities, for whom the ability to secure a job is hindered by the homogeneous group stereotype of Blacks as being criminal, unreliable, and untrustworthy.

Although they benefit from better wages and living in more integrated communities, middle- and upper-class Blacks also experience negative consequences of a homogenized version of the African American experience. According to Neckerman, Carter, and Lee (1999), the increased contact with Whites that comes with middle-class lifestyles results in more everyday and subtle experiences of racism in public facilities and on the street. According to Feagin (1991), middle-class Blacks report avoidance, poor service, verbal epithets, public threats, and various forms of harassment from Whites with whom they come in contact. As such, even though middle-class Blacks have achieved higher status in terms of educational attainment, occupational prestige, and wealth, they continue to be treated poorly by Whites. This treatment is based on the homogeneous perspective that all Blacks are the same, leading to the assumption that one's middle-class Black neighbors, coworkers, or co-commuters are actually members of the underclass.

Neckerman et al. (1999) suggest that to avoid such incidents, middle-class Blacks adapt by "wearing a mask" in racially integrated spaces highlighting their ability to use the speech and behavioral patterns valued by other (White) middleclass participants in the integrated space. This analysis implies that middle-class Blacks use different speech and behavioral patterns in intraracial/interclass spaces where "African American" symbolic and interaction styles are highly valued. An alternative perspective is that middle-class Blacks "wear a mask" of what they believe to be stereotypical (lower-class) Black patterns in interclass settings to validate inclusion in a presumptively homogeneous group. 
Thus, it may be the case that middle-class Blacks alter their behavior in educational and occupational settings in the same way that middle-class Whites do, to abide by classroom and office decorum. To suggest that middle-class Blacks adapt to "White" speech and behavior patterns in educational and occupational settings predominated by Whites is to suggest an opposite Black speech and behavior that would be more appropriate and comfortable for them. Particularly, it suggests that African Americans, even those who grew up in middle-class homes, prefer to speak and act like lower-class people who are "Black," but they suppress it to be successful.

To be sure, how one performs - one's ability to adapt to the cultural norms of the environment - will determine one's ability to be successful. It may be the ability to fit comfortably in (White) middle-class norms that distinguishes middlefrom lower-class Blacks. The reality may be that middle-class Blacks are not adapting to "White middle-class norms" but merely living the way they grew up-and by being middle class, are better equipped to secure jobs, careers, academic success, and attainments.

\section{Gender Differences}

In the previous section we outlined ways that the monolithic representation of African Americans subsumes class differences; in this section we outline the ways it erases gender differences as well. The Black experience is generally defined by the male Black experience. This includes the harmful threat of police brutality, the harassment of "driving while Black," and the increased likelihood of being a victim of violent crime, of being incarcerated, and of dying before the age of 25 (Staples, 1991). Although many of these experiences may be considered more of a lower-class problem, such things as police brutality and everyday racism transcend class (Feagin, 1991; Judd, Park, Ryan, Brauer, \& Kraus, 1995). What matters, henceforth, has less to do with a man's particular class position per se and more to do with his appearance. Accordingly, when Judd and his colleagues (1995) had students list stereotypes about African Americans, the negative depictions presented, such as hostile and intimidating, resonate more as characteristics of young, Black, lower-class men than of middle-class men. According to Neckerman et al. (1999) "whites tend to assume that all black strangers are lower-class and respond accordingly, with fear, insult, or threat" (p. 953). In this way, outgroup stereotypes about Blacks target lower-class Black males but also assume that all Black males are lower class.

The monolithic presentation of African Americans affects women differently than it does men. Whereas the stereotypes about Black men elicit fear and hostility from outgroups, stereotypes about Black women elicit derision and sexual intrigue. For instance, according to Winant (1997), stereotypes about the Black "welfare queen" were used to fuel anti-Black sentiment against welfare policies during both 
the Reagan and Bush administrations. This sanctioned the withdrawal of federally funded programs geared toward the training and employment of Black women and men by scapegoating Black women. Likewise, the stereotype about the Black Jezebel has served to sanction the rape of Black women by Black and non-Black men alike (Collins, 1990).

Furthermore, whereas the "welfare queen" stereotype is class-based, the Black mammy and Jezebel stereotypes transcend class barriers. These class- and non-class-based stereotypes about Black women are as debilitating as are those depicting Black men as unemployed and criminal, yet both knowledge about the stereotypes and its consequences are less acknowledged (Collins, 1990; Crenshaw, 1991). According to authors such as Collins (1990), Crenshaw (1991), and Glenn (1992), these oppressive depictions of Black women help justify poor treatment and even violence against Black women at the hands of Black men because women are defined so narrowly. In this way, negative stereotypes about men are more public, which offers room for rebuttal. Alternatively, that Black women are negatively stereotyped remains relatively submerged and unquestioned.

In this way, Black women are distanced from Black men, leaving them in a vulnerable position that allows for negative treatment (see Everett Hughes, 1971, regarding the creation of outgroup status). As such, when issues pertaining to Black women are presented in large forums, they are often attacked and belittled. For instance, when Alice Walker's novel The Color Purple was made into a film, outspoken African Americans criticized it for depicting Black men negatively, as violent domestic abusers (Bobo, 1995). Although sexual and domestic violence are real issues for Black women, discussing these issues publicly contributes to the negative stereotype of the "violent Black male." As such, Black women are expected to suffer in silence so that Black men will not be viewed more negatively than they already are. This denial of Black women's issues in favor of what is considered the "Black community's" issues is due to the fact that "Black issues" are often defined by Black men (Collins, 1990). Black women's issues also escape discussions of "women's issues" because White women generally define what "women's issues" are. Thus, Black women's subordination is found at the intersection of race and gender, rendering Black women a marginalized group among the outgroup and ingroup in both race and gender (Crenshaw, 1991).

The presentation of a homogenous Black experience in academic literature and popular culture contributes to the silencing of Black women and men alike. One way this is accomplished is by defining the "Black" experience by the "male" experience, which mandates the oppression of Black women and assumes that the male experience is also uniform. This is more than a simple overgeneralization; it is a structured system of racial homogenization that results in the silence of multiple voices from women and men of African descent. Specifically, this system of racial homogenization mandates the use of stereotypes for ingroup and outgroup interactions, erasing the experiences of women, men, middle-class, and immigrant 
people of African descent from academic literature, popular culture, and, most importantly, daily interactions.

\section{Skin Tone}

Homogeneous depictions of African Americans not only erase class and gender distinctions, they erase the correlation between class, gender, and skin tone. According to Keith and Herring (1991), Black women are the ones most debilitated by skin tone distinctions. They found that for women, darker skin was positively correlated to fewer years of education, less prestigious occupations, and lower family incomes (Keith \& Herring, 1991). This suggests that African American experiences are more heterogeneous than homogeneous. In the literature, skin tone has been found to determine the type of SES, occupational experience, and sense of attractiveness one has.

Socioeconomic status. According to data collected from the National Survey of Black Americans, lighter skinned Blacks in general have more years of education, higher incomes, and higher SES than darker skinned African Americans (Keith \& Herring, 1991). The magnitude of this disparity between light- and dark-skinned African Americans equals the size of the gap between Black and White America in respect to education, income, and SES (M. Hughes \& Hertel, 1990). The link between skin tone and socioeconomic disparities among African Americans is not new (Russell, Wilson, \& Hall, 1992). But it is unclear if this linkage is simply due to the perpetuation of the historic advantage of parents through better life chances to their children or if in moment-to-moment interactions the daily experiences of lighter skinned African Americans are more supportive and fostering, less subject to negative and stigmatizing interactions, than those of darker skinned Blacks.

Once more, it should be clear that this SES distinction is different for women and men. As Keith and Herring (1991) found for women, darker skin was positively correlated to fewer years of education, less prestigious occupations, and lower family incomes. More recent findings suggest that skin tone for women is less correlated to being working class or professional (Krieger, Sidney, \& Coakley, 1998). Krieger et al. (1998) found that working-class men, however, were 1.4 times more likely to be darker skinned than professional men. These findings suggest that for Black women SES is becoming less related to skin tone, whereas for Black men the correlation continues to exist. To have a better understanding as to whether this is the case, we might look toward the next set of data from the National Survey on Black Americans.

Skin tone and workplace disparity. Skin tone-based advantage is often assumed to be a historic legacy. It is assumed that having lighter skin affords 
advantages in the workplace for all Americans, whether of African, European, or other background (Bell, 1996). Among African Americans, it is often assumed that Whites prefer lighter skinned African Americans. This belief may explain why lighter skinned African American college students reported higher occupational aspirations than their darker skinned counterparts (Hall, 1996). It suggests that African Americans aspire to what they perceive to be more attainable: higher occupational possibilities for lighter than darker skinned African Americans.

Although Russell et al. (1992) suggest that there is a definite skin tone bias in favor of lighter skinned Blacks among African American employers, evidence of this is difficult to capture. Ronald Turner (1995) analyzed both court cases in which a light-skinned employee charged a dark-skinned supervisor with skin tone-based discrimination and those in which a dark-skinned employee charged a light-skinned supervisor with preferential treatment of other light-skinned employees. In each lawsuit the employee attempted to use Title VII from the 1964 Civil Rights legislation, which prohibits employers from discriminating against a person based on race, color, creed, sex, religion, or national origin. Each type of case, however, was dismissed for lack of a preponderance of evidence. This does not mean that workplace discrimination between light- and dark-skinned Blacks does not occur. It means that proving it can be difficult, perhaps more difficult than proving interracial discrimination.

Skin tone as a marker of beauty. As we have seen, skin tone has been linked to SES and workplace experiences. What may be the most central issue, however, is the connection between skin tone and notions of attractiveness. Research suggests that perceived attractiveness bolsters self-worth (Dion, Pak \& Dion, 1990; Hall, 1995; Umberson \& Hughes, 1987). If individuals with lighter or darker skin are considered more attractive, then they are more likely to be treated better in all settings: intraracial and interracial. Those found attractive are held, cuddled, and kissed more as infants and considered more sociable, warm, interesting, outgoing, humorous, and socially adept as adults (Zanden \& Wilfrid, 1997; Feingold, 1992). Therefore, if skin tone is linked to attractiveness, those with lighter skin tone will be treated more favorably in everyday interactions.

In general, skin tone as a marker of beauty is gendered, having different consequences for men and women. For instance, to women, darker skin is supposedly related to a more negative sense of self-worth (Neal \& Wilson, 1989; Harvey, 1995). Alternately, in a study by Wade (1996), dark-skinned men rated themselves as being more attractive than lighter skinned men. In this sense, skin tone may be more valuable for light-skinned women and dark-skinned men. The consequences for lighter skinned men may be less debilitating than those for darker skinned women because men are able to exchange their wealth for marriage partners and men are judged less by their physical appearance than are women. Therefore, as 
Keith and Herring (1991) suggested, skin tone distinctions are most debilitating for Black women.

It is suggested that successful Black men, regardless of their skin tone, exchange their wealth for a woman's lighter skin (Drake \& Cayton, 1945; Okazawa-Rey, Robinson, \& Ward, 1987; Hall, 1995). This exchange, if an exchange at all, is vilified as being "color struck," a "bleaching syndrome" (Hall, 1995), and explained as "the pathological effects of color consciousness" (Okazawa-Rey, Robinson, \& Ward, 1986, p. 13). Calling the potential preference for light-skinned women by men "pathological" belies evidence that women may have a similar preference for darker skinned men. ${ }^{3}$ Likewise, it mandates an "appropriate" preference that individuals should have regarding skin tone-dark over light—and it neglects the potential for material gain found through marriage to someone lighter, not just in the United States, but globally (see Degler, 1971, for examples).

Bias against "very dark" and "very light" African Americans. To be clear, skin tone has been found to affect all African Americans, dark and light. It is considered a more pertinent topic, however, for those who are considered "very dark" and "very light." For instance, Hall (1992) found that medium skin tone is less stigmatized than being light or dark skinned among African Americans. This suggests that the experience of being Black is heterogeneous at another level: light skinned, medium skinned, and dark skinned. Understanding why this is the case may have something to do with the way African Americans are socialized. Within primary groups, African American children learn about the significance of skin tone when and if they see people treated better or worse based upon having lighter or darker skin (see Porter, 1991, for examples of child skin tone preferences).

It is not possible to say, however, that the messages a child receives favoring one particular skin tone over the other will be consistent. For instance, a Black child may hear statements like "You don't need any more sun," suggesting that s/he is "too dark." Yet, s/he may hear the same person say, "The darker the berry the sweeter the juice," suggesting the richness of dark skin. In I Know Why the Caged Bird Sings, Maya Angelou wrote "I was described by playmates as being shit color, he was lauded for his velvet-black skin" (1969, p. 17). The high value placed on dark skin in Angelou's text is contrasted with the attitude of April Sinclair's (1994) character Jean in Coffee Will Make You Black, who says, "My skin was the color of Cracker Jacks. But most Negroes didn't get excited over folks who were darker than a paper bag" (p. 4). These competing messages about beauty

\footnotetext{
${ }^{3}$ Comedians, such as Pier, have mentioned the shift in Black women's preferences over the past 10 years toward darker skinned Black men. This can also be supported by the increased prevalence of leading men in major motion pictures and top Black male models who have darker skin.
} 
as it relates to skin tone are widely acknowledged among many African Americans. The result is a heightened level of consciousness about one's skin tone, the skin tone of others, and how it is valued differently dependent on the setting.

Among the ingroup, there is no standard value to skin tone. This can be best illustrated in the oral tradition of "signifying" and "playing the dozens," a linguistic game in which people make jokes about one's mother or "kinfolk." The jokes illustrate how skin tone bias does not always exalt light over dark among African Americans but points to the bias within the "Black community" against being "too dark/Black" and "too light/White." Here are some examples of jokes collected by Christopher White (1994) that illustrate the skin tone bias among African Americans:

Yo Momma is so black ... when she opens her eyes it looks like a train is coming.

Yo Momma is so black she has to wear gloves when she eats a tootsie roll to keep from eating her fingers.

Yo Momma is so light bright damn near white the Klan uses her as a poster child.

Yo Momma is so light and yellow you all need sun block to keep from looking like burnt toast. (pp. 24-25)

Young men and women that grow up hearing expressions such as these learn how value is placed on skin tone. Although these distinctions are pointed out as asides or humorously, laughing at one's pain may be seen as a coping mechanism to deal with issues that are very real and significant. In short, the skin tone bias among African Americans both exalts light skin tone and denigrates it. Light skin may act as kind of currency in one situation, facilitating entry, and as a barrier and source of exclusion in another. How people construct meaning in each setting will determine if light or dark skin acts as a source of advantage, disadvantage, or is altogether unimportant.

Context specific distinctions. Skin tone will have different significance in settings that are exclusively ingroup than it will in interracial outgroup settings. As the previous section illustrates, the value ascribed to skin tone is variable among African Americans but generally holds medium skin tone as the ideal because it is less stigmatized (Hall, 1992). Between-group/intraracial interactions may feel more comfortable with someone who looks relatively similar to the self. This may be why being considered "very dark" or "very light" is highly stigmatized. Sometimes this means that light skin tone is viewed as a lack of racial purity and dark skin is viewed as more beautiful, familiar, or real (Bond \& Cash, 1992; Hall, 1992, 1995; Keenan, 1996; Wade, 1996). On the other hand, sometimes it means that light skin is viewed as more attractive and indicative of material wealth, which means better treatment and preference (Drake \& Cayton, 1945; Hall, 1995; Okazawa-Rey et al., 1987).

Interracial settings may offer African Americans with lighter skin better treatment from Whites more often than do intraracial settings. Although it is difficult to 
claim Whites feel closer to lighter skinned Blacks because of physical resemblance to Whites, it may be that most negative stereotypes are associated with darker skinned blacks. Therefore, light-skinned blacks may be seen as more likeable and less threatening. Because of this, interracial settings are thought to offer more advantages to lighter skinned than to darker skinned African Americans as a general rule. In contrast, intraracial settings may offer advantages and consequences, depending on the situation, for both dark- and light-skinned African Americans.

Skin tone has been related to self-worth, both because being light has been valued (Hudson, 1995) and because being "too light" has been denigrated (Pinderhughes, 1995). Skin tone and physical appearance may influence relationships both among African Americans and between White and Black Americans, even though Whites do not make the same kinds of distinctions that Black Americans make (Baynes, 1997). Within-group interactions may be better for lightskinned African Americans when the other views skin tone as a marker of access to resources or a symbol of beauty. Furthermore, these advantages and consequences may be gender specific, affecting men and women differently in each domain. This is because of the differential importance of beauty and physical appearance for women and men, such that for women, physical appearance and perceived beauty may be a more general advantage than for men (Pinker, 1997).

\section{Future Research: Heterogeneous Racial Group Perspective}

We have highlighted the difficulty of looking at race from a homogeneous racial group perspective, arguing that the everyday experience of being African American is not homogenous but rather that race combines with social class, gender, and importantly skin tone to provide very different everyday experiences for African Americans. Economic and social disparities between darker and lighter skinned African Americans imply that skin tone has enormous implications for everyday life hassles and stressors and the type of unfair or racist treatment experienced. To understand how distinction may be correlated to skin tone it may be helpful to see how it acts as a marker of beauty not separate from but in conjunction with other markers of beauty, turning on positive responses of others when skin tone cues attractiveness. In the same way darker skin does not necessarily result in negative interactions or negative attractiveness cues, especially in contexts where authenticity of Black experience is valued.

By thinking heterogeneously about race, we can also ask if the more positive economic experience of lighter skinned African Americans can be informative of the nature of stereotypes and their consequences for darker skinned African Americans. That is, as researchers we can begin to explore the race by social class nexus of stereotyping and better understand the experiences of targets of stereotypes. Such a line of research can also explicate the nature of stereotypes about men and women separately as well as the potential for gendered responses to stereotypes. 
By examining the extent to which skin tone or other physical markers can serve to activate or deactivate these stereotypes and the ways that physical differences are internalized as part of the identity of ingroup members, a heterogeneous model can provide more specific predictions about the consequences of stereotyping.

The heterogeneous race model also allows us, as researchers, to focus our attention more specifically on the nature of the race by social class and gender nexus of stereotyping and its pernicious effects for those with fewer economic resources to protect themselves. A heterogeneous model allows for analyses of both inter- and intragroup interactions for the stereotypes and responses they elicit from targets. For example, intraracial skin tone advantages may be at the expense of other African Americans because advantage is given to some, not others, within the group. Thus the heterogeneous race model highlights the need to distinguish the nature of the situation-economic or interpersonal, within or between gender, racial, or economic groups - if we are to understand the meaning of racial identity and responses to stereotypes.

\section{Conclusion}

Although mentioning differences among African Americans may disrupt the conventional ways we think about and study race, without mentioning these differences, social science will remain out of touch with social reality. By addressing the different experiences of African Americans based on class, gender, and physical appearance/skin tone, we are able to illustrate how race is experienced, not for an abstract African American, but for a more specific, tangible human being. If the desire of social scientists is to break down stereotypes rather than perpetuating them, approaching the study of groups-racial, gender, etc.-from a heterogeneous perspective is a new and effective way to work toward that goal.

\section{References}

Angelou, M. (1969). I Know Why the Caged Bird Sings. New York: Random House.

Arroyo, C., \& Zigler, E. (1995). Racial identity, academic achievement, and the psychological wellbeing of economically disadvantaged adolescents. Journal of Personality and Social Psychology, 69, 903-914.

Asante, M. (1980). Afrocentricity: A theory of social change. Buffalo: Amulefi.

Balibar, E. (1996). Fictive ethnicity and ideal nation. In J. Hitchinson \& A. Smith (Eds.), Ethnicity (pp. 164-168). New York: Oxford University Press.

Baynes, L. (1997). If it's not just Black and White anymore, why does darkness cast a longer discriminatory shadow than lightness? An investigation and analysis of the color hierarchy. Denver University Law Review, 75, 131-185.

Bell, D. (1996). Ethnicity and social change. In J. Hitchinson \& A. Smith (Eds.), Ethnicity (pp. 138-146). New York: Oxford University Press.

Bobo, J. (1995). Black women as cultural readers. New York: Columbia University Press.

Bond, S., \& Cash, T. (1992). Black beauty-Skin color and body images among African American college-women. Journal of Applied Social Psychology, 22, 874-888.

Collins, P. (1990). Black feminist thought. Boston: Unwin Hyman. 
Coon, H., \& Kemmelmeier, K. (in press). Cultural orientations in the United States: (Re-)Examining differences among racial/ethnic groups. Journal of Cross Cultural Psychology.

Crenshaw, K. (1991). Beyond racism and misogyny: Black feminism and 2 Live Crew. Boston Review, $16,6-33$.

Crocker, J. (1999). Social stigma and self-esteem: Situational construction of self-worth. Journal of Experimental Social Psychology, 35(1), 89-107.

Crocker, J., Luhtanen, R., Blaine, B., \& Broadnax, S. (1994). Collective self-esteem and psychological well-being among White, Black, and Asian college students. Personality and Social Psychology Bulletin, 20(5), 503-513.

Cross, W. (1971). The Negro-to-Black conversion experience. Black World, 20, 13-26.

Cross, W., \& Fhagen-Smith, P. (1996). Nigrescence \& ego identity development: Accounting for differential Black identity patterns. In P. Pederson (Ed.), Counseling across cultures (4th ed., pp. 108-123). Thousand Oaks, CA: Sage.

Degler, C. (1971). Neither Black nor White: Slavery and race relations in Brazil and the United States. New York: Macmillan.

Dion, K., Pak, A., \& Dion, K. (1990). Stereotyping physical attractiveness: A sociocultural perspective. Journal of Cross-Cultural Psychology, 21, 378-398.

Drake, S., \& Cayton, H. (1945). Black metropolis. New York: Harcourt Brace.

Feagin, J. (1991). The continuing significance of race: Anti-Black discrimination in public places. American Sociological Review, 56, 101-116.

Feingold, A. (1992). Good-looking people are not what we think. Psychological Bulletin, 111, 304-341.

Fordham, S. (1988). Racelessness as a factor in Black students' school success: Pragmatic strategy or Pyrrhic victory? Harvard Educational Review, 58, 54-84.

Gans, H. (1996). Symbolic ethnicity. In J. Hitchinson \& A. Smith (Eds.), Ethnicity (pp. 146-155). New York: Oxford University Press.

Glenn, E. (1992). From servitude to service work: Historical continuities in the racial division of paid reproductive labor. Signs, 18(1), 1-43.

Graham, L. (1999). Our kind of people: Inside America's Black upper class. New York: Harper.

Graham, S. (1994). Motivation in African Americans. Review of Educational Research, 64, 55-117.

Hall, R. (1992). Bias among African-Americans regarding skin color: Implications for social work practice. Research on Social Work Practice, 2, 479-486.

Hall, R. (1995). The bleaching syndrome: African Americans' response to cultural domination vis-à-vis skin color. Journal of Black Studies, 26, 172-184.

Hall, R. (1996). Occupational aspiration among African-Americans: A case for affirmative action. Journal of Sociology and Social Welfare, 23(4), 117-128.

Harvey, A. (1995). The issue of skin color in psychotherapy with African Americans. Families in Society: The Journal Of Contemporary Human Services, 76, 3-10.

Hollinger, D. (1999). National culture and communities of descent. In N. Smelser \& J. Alexander (Eds.), Diversity and its discontents: Cultural conflict and common ground in contemporary American society (pp. 247-262). Princeton, NJ: Princeton University Press.

Hudson, B. (1995). Images used by African Americans to combat negative stereotypes. In H. Harris, H. Blue, \& E. Griffith (Eds.), Racial and ethnic identity (pp. 135-172). New York: Routledge.

Hughes, E. (1971). Good people and dirty work. In The Sociological Eye: Selected Papers on Institutions and Race. Chicago: Aldine.

Hughes, M., \& Hertel, B. (1990). The significance of color remains: A study of life chances, mate selection, and ethnic consciousness among Black Americans. Social Forces, 68, 1105-1120.

Judd, C., Park, B., Ryan, C., Brauer, M., \& Kraus, S. (1995). Stereotypes and ethnocentrism: Diverging interethnic perceptions of African American and White American youth. Journal of Personality and Social Psychology, 69(3), 460-481.

Keenan, K. (1996). Skin tones and physical features of Blacks in magazine advertisements. Journalism \& Mass Communication Quarterly, 73, 905-912.

Keith, V., \& Herring, C. (1991). Skin tone and stratification in the Black community. American Journal of Sociology, 97, 760-778. 
Kirschenman, J., \& Neckerman, K. (1991). "We'd love to hire them, but . ..": The meaning of race for employers. In C. Jencks \& P. Peterson (Eds.), The urban underclass (pp. 203-232). Washington, DC: Brookings Institute.

Krieger, N., Sidney, S., \& Coakley, E. (1998). Racial discrimination and skin color in the CARDIA study: Implications for public health research. American Journal of Public Health, 88, 13081313.

Leibow, E. (1967). Tally's corner: A study of Negro street corner men. Boston: Little, Brown.

Massey, D., \& Denton, N. (1993). American apartheid: Segregation and the making of the underclass. Cambridge, MA: Harvard University Press.

Moynihan, D. (1971). The tangle of pathology. In R. Staples (Ed.), The Black family: Essays and studies. Belmount, CA: Wadsworth.

Neal, A., \& Wilson, M. (1989). The role of skin color and features in the Black community: Implications for Black women and therapy. Clinical Psychology Review, 9, 323-333.

Neckerman, K., Carter, P., \& Lee, J. (1999). Segmented assimilation and minority cultures of mobility. Ethnic and Racial Studies 22(6), 945-965.

Nettles, M., \& Perna, L. (1997). The African American education data book. Fairfax, VA: United Negro College Fund.

Okazawa-Rey, M., Robinson, T., \& Ward, J. (1986). Black women and the politics of skin color and hair. Women's Studies Quarterly, 14(1\&2), 13-14.

Okazawa-Rey, M., Robinson, T., \& Ward, J. (1987). Black women and the politics of skin color and hair. Women and Therapy, 6, 89-102.

Oliver, M., \& Shapiro, T. (1995). Black wealth, White wealth: A new perspective on racial inequality. New York: Routledge.

Oyserman, D., Coon, H., \& Kemmelmeier, M. (in press). How individualist are Americans? American relationality and other lessons from cultural and cross-cultural research. Psychological Bulletin.

Oyserman, D., Harrison, K., \& Bybee, D. (in press). Can racial identity be promotive of academic efficacy in adolescence? International Journal of Behavior Development.

Phinney, J. (1992). The Multigroup Ethnic Identity Measure: A new scale for use with adolescents and youth adults from diverse groups. Journal of Adolescent Research, 7, 156-176.

Phinney, J. (1996). When we talk about American ethnic groups, what do we mean? American Psychologist 51(9), 918-927.

Pinderhughes, E. (1995). Biracial identity-Asset or handicap? In H. Harris, H. Blue, \& E. Griffith (Eds.), Racial and ethnic identity (pp. 73-94). New York: Routledge.

Pinker, S. (1997). How the mind works. New York: W.W. Norton.

Porter, C. (1991). Social reasons for skin tone preferences of Black school-age children. American Journal of Orthopsychiatry, 61, 149-154.

Quadagno, J. (1994). The color of welfare: How racism undermined the war on poverty. New York: Oxford University Press.

Russell, K., Wilson, M., \& Hall, R., (1992). The color complex: The politics of skin color among African Americans. New York: Harcourt Brace Jovanovich.

Sinclair, A. (1994). Coffee will make you Black. New York: Hyperion.

Staples, R. (1991). Black male genocide: A final solution to the race problem in America. In B. Bowser, (Ed.), Black male adolescents: Parenting and education in community context (pp. 39-57). New York: University Press of America.

Turner, R. (1995). The color complex: Intraracial discrimination in the workplace. Labor Law Journal, 46, 678-684.

Umberson, D., \& Hughes, M. (1987). The impact of physical attractiveness on achievement and psychological well-being. Social Psychology Quarterly, 50, 227-236.

Wade, T. J. (1996). The relationship between skin color and self-perceived global, physical, and sexual attractiveness, and self-esteem for African Americans. Journal of Black Psychology, 22, $358-373$

White, C. (Ed.) (1994). The "Yo Momma" joke book. Self-published.

Whittler, T., Calantone, R., \& Young, M. (1991). Strength of ethnic affiliation: Examining black identification with black culture. Journal of Social Psychology, 131, 461-467.

Williams, D., \& Collins, C. (1995). US socioeconomic and racial differences in health: Patterns and explanations. Annual Review of Sociology, 21, 349-386. 
Wilson, W. (1987). The truly disadvantaged: The inner city, the underclass, and public policy. Chicago: University of Chicago Press.

Winant, H. (1997). Racial dualism. In W. Lubiano (Ed.), The house that race built: Black Americans, U.S. terrain (pp. 87-115). New York: Pantheon.

Wood, P., \& Chesser, M. (1994). Black stereotyping in a university population. Sociological Focus, 27, 17-34.

Zanden, V., \& Wilfrid, J. (1997). Social psychology (4th ed.). New York: Random House.

AARON CELIOUS is a doctoral student in Sociology at the University of Michigan. He is funded through a National Science Foundation fellowship and a Supplement Award to the Pathways for Youth: Risk and Resilience (Oyserman, Principal Investigator), funded by the National Institute of Mental Health, to study the implications of skin tone for racial identity and well-being among African American youth, particularly high-risk youth.

DAPHNA OYSERMAN obtained her PhD from the University of Michigan, where she is an Associate Research Scientist at the Research Center for Group Dynamics, Institute for Social Research, and an Associate Professor in the Department of Psychology and School of Social Work. Her research focuses on the interplay between cultural contexts, identity, and the sense individuals make of their possibilities and the strategies likely to help them attain their life goals. Currently she is studying the influence of racial and ethnic minority identity schemas on sensitivity to stereotyping and engagement in school among adolescents and responses to everyday discrimination experiences among community adults. Research funded by the National Institute of Mental Health includes a racialidentity-focused preventive intervention aimed at promoting school persistence and reducing dropout. 